\title{
PROJECT : PEMANFAATAN LAPISAN SOIL DIATAS RAWA UNTUK REVEGETASI DI AREA PIT WEST SITE LATI MINE OPERATION - PT. BERAU COAL
}

\author{
Arintoko Saputro $^{1)^{*}}$, Zaki Setia Nugraha $^{2)^{* * *}}$, Ikhsan Setiawan $)^{3 * *}$, Jangkung Wibowo $^{4)^{* * *}}$ \\ *LMO Mine Manager, PT. Berau Coal \\ **Short Term Mine Plan Department, PT. Berau Coal
}

\begin{abstract}
ABSTRAK
Pit West pada site Lati Mine Operation (LMO) merupakan salah satu Pit terbesar di PT. Berau Coal dengan target produksi 2019 untuk overburden removal sebesar 166.007.173 BCM dan batubara sebesar 13.475.859 MT. Dengan rencana bukaan lahan seluas 146 Ha dan rencana revegetasi seluas $235 \mathrm{Ha}$. Area rawa yang masuk di dalam rencana bukaan lahan adalah seluas $88 \mathrm{Ha}(60 \%$ dari rencana bukaan lahan) dengan kedalaman rawa rata-rata mencapai $25-30 \mathrm{~m}$. Besarnya luasan area rawa yang masuk dalam rencana bukaan lahan dan tingginya rencana revegetasi dengan kebutuhan soil sebesar 2.937.500 BCM menjadi latar belakang dari project ini dilakukan. Berdasarkan perhitungan potensi lapisan soil di atas rawa yang dapat dimanfaatkan adalah sebesar 2.201.860 BCM. Secara kualitas dan kesuburan tanah belum dilakukan analisis. Melihat potensi ini dibentuklah project initiative dengan tujuan memanfaatkan lapisan soil di atas rawa untuk digunakan sebagai media tanam revegetasi. Department in charge (DIC) project ini adalah short term mine planner, enviro, operation, dan pit service. Metode analisa project yang digunakan adalah problem, identification, corrective, action (PICA). Penentuan lokasi dumping menjadi faktor penting karena material lapisan soil di atas rawa yang dapat didumping hanya pada area datar dan tidak diperkenankan pada area slope disposal karena pertimbangan safety serta teknis operasional. Secara bersamaan lapisan soil di atas rawa diloading dengan teknis layering front loading untuk membentuk pad excavator. Treatment lapisan soil di atas rawa membutuhkan waktu yang lebih lama bila dibandingkan dengan treatment soil original karena material dalam kondisi basah. Material lapisan soil di atas rawa area pit (source) dan revegetasi (destination) dilakukan sampling dengan metode teknik sampling systematic random sampling untuk mengetahui kualitas lapisan soil di atas rawa dengan 12 parameter pengujian diantaranya $\mathrm{PH}-\mathrm{H} 2 \mathrm{O}, \mathrm{C}$-organik, N-total, $\mathrm{P} \&$ K-potential, P-tersedia, C/N organik, K-tersedia, KTK, K Na Ca Mg, \% kejenuhan basa, Al \& H, dan \% Kejenuhan Al. Secara keseluruhan sesuai hasil uji laboratorium kandungan unsur hara lapisan soil diatas rawa hampir sama baik dengan soil pada area original. Berdasarkan kajian dan rekomendasi enviro lapisan soil di atas rawa secara kandungan sifat kimia layak untuk digunakan sebagai media pertumbuhan tanaman untuk revegetasi. Melalui project ini area revegetasi yang telah dicover dengan material lapisan soil di atas rawa (November 2018-Juni 2019) sebagai bagian konservasi lingkungan adalah seluas 41,20 Ha dengan pencapaian year to date 2019 revegetasi hingga Juni adalah $100 \%$ (actual 109,11 Ha, plan 108,79 Ha).
\end{abstract}

Keyword : soil, rawa, revegetasi

\begin{abstract}
Pit West on the Lati Mine Operation (LMO) site is one of the largest pits at PT. Berau Coal with a production target of 166,007,173 BCM 2019 for overburden removal and coal of 13,475,859 MT on 2019, with a planned mine area of $146 \mathrm{Ha}$ and revegetation plan area of $235 \mathrm{Ha}$. The swamp area included in the land clearing plan is 88 hectares (60\% of the land clearing plan) with an average swamp depth of 25-30 $\mathrm{m}$. Large size of the swamp area included in the land clearing plan and soil requirements of 2,937,500 BCM for revegetation plan be the background of this project. Based on the calculation of the potential layer of soil above the swampy material that can be used for revegetation is 2,201,860 BCM. In terms of quality and soil fertility, there has not been
\end{abstract}


analyzed. Based on this case, a project initiative was formed with the aim of utilizing the soil layer above the swampy material for use as revegetation plant. People in charge on this project are short term mine planner, environment, operation, and pit service section. Problem, identification, corrective, action (PICA) used as problem identification method. Determination of the dumping location becomes an important factor because the soil layer material above the swampy material can only be dumped on a flat area and not allowed in the slope disposal area due to safety considerations and operational techniques. Simultaneously the soil layer above the swampy material is loaded with special method to form an excavator pad. Treatment of the soil layer above the swampy material takes wider than the original soil treatment because the material is wet. Soil layer material above the pit area (source soil) and revegetation (destination) was carried out sampling by systematic random sampling technique to determine the quality of the soil layer above the swamp with 12 test parameters including $\mathrm{PH}-\mathrm{H} 2 \mathrm{O}, \mathrm{C}$-organic, $\mathrm{N}$-total, $\mathrm{P} \& \mathrm{~K}$-potential, $\mathrm{P}$ available, organic $\mathrm{C} / \mathrm{N}, \mathrm{K}$-available, $\mathrm{CEC}, \mathrm{K} \mathrm{NaCa} \mathrm{Mg}$, \% base saturation, $\mathrm{Al} \& \mathrm{H}$, and\% $\mathrm{Al}$ saturation According to the results of laboratory tests the nutrient content of the soil layer above the swamp is almost as good as the soil in the original area. Based on the study and recommendations, layer of soil above the swamp the chemical properties are suitable for use as plant growth media for revegetation. Through this project the revegetation area that has been covered with soil layer material above the swamp (November 2018-June 2019) as part of environmental conservation is $41.20 \mathrm{Ha}$ with the achievement of year to date 2019 revegetation until June is 100\% (actual 109.11 Ha, plan $108.79 \mathrm{Ha}$ )

Keyword: soil, swamp, revegetation

\section{A. PENDAHULUAN}

Area rawa (swamp) adalah area yang sepanjang tahun, atau selama waktu yang panjang dalam setahun selalu jenuh (saturated) atau tergenang (waterlogged) air dangkal hampir sepanjang waktu dalam setahun. Air umumnya tidak bergerak atau tidak mengalir dan bagian dasar soil berupa lumpur. Dalam kondisi alami, swamp ditumbuhi oleh berbagai vegetasi dari jenis semak-semak sampai pohon-pohonan dan di daerah tropika biasanya berupa hutan rawa atau hutan gambut (Monkhouse dan Small, 1978)

Pit West pada site Lati Mine Operation (LMO) merupakan salah satu Pit terbesar di PT. Berau Coal dengan target produksi 2019 untuk overburden removal sebesar 166.007.173 BCM dan batubara sebesar 13.475.859 MT. Dengan rencana bukaan lahan seluas 146 Ha dan rencana revegetasi seluas $235 \mathrm{Ha}$. Area rawa yang masuk di dalam rencana bukaan lahan adalah seluas 88 Ha (60\% dari rencana bukaan lahan) dengan kedalaman rawa rata-rata mencapai $25-30 \mathrm{~m}$. Besarnya luasan area rawa yang masuk dalam rencana bukaan lahan dan tingginya rencana revegetasi dengan kebutuhan soil sebesar 2.937.500 BCM menjadi latar belakang dari project ini dilakukan.

\section{B. METODOLOGI}

Penentuan lokasi dumping menjadi faktor penting karena material lapisan soil diatas rawa yang dapat di dumping hanya pada area datar dan tidak diperkenankan pada area slope disposal karena pertimbangan safety serta teknis operasional. Secara bersamaan pada area front loading lapisan soil diatas rawa di loading dengan teknis layering front loading untuk membentuk pad excavator. Layering adalah pelapisan material lunak dengan material overburden yang betujuan untuk meningkatkan daya dukung tanah (mencegah unit amblas). 


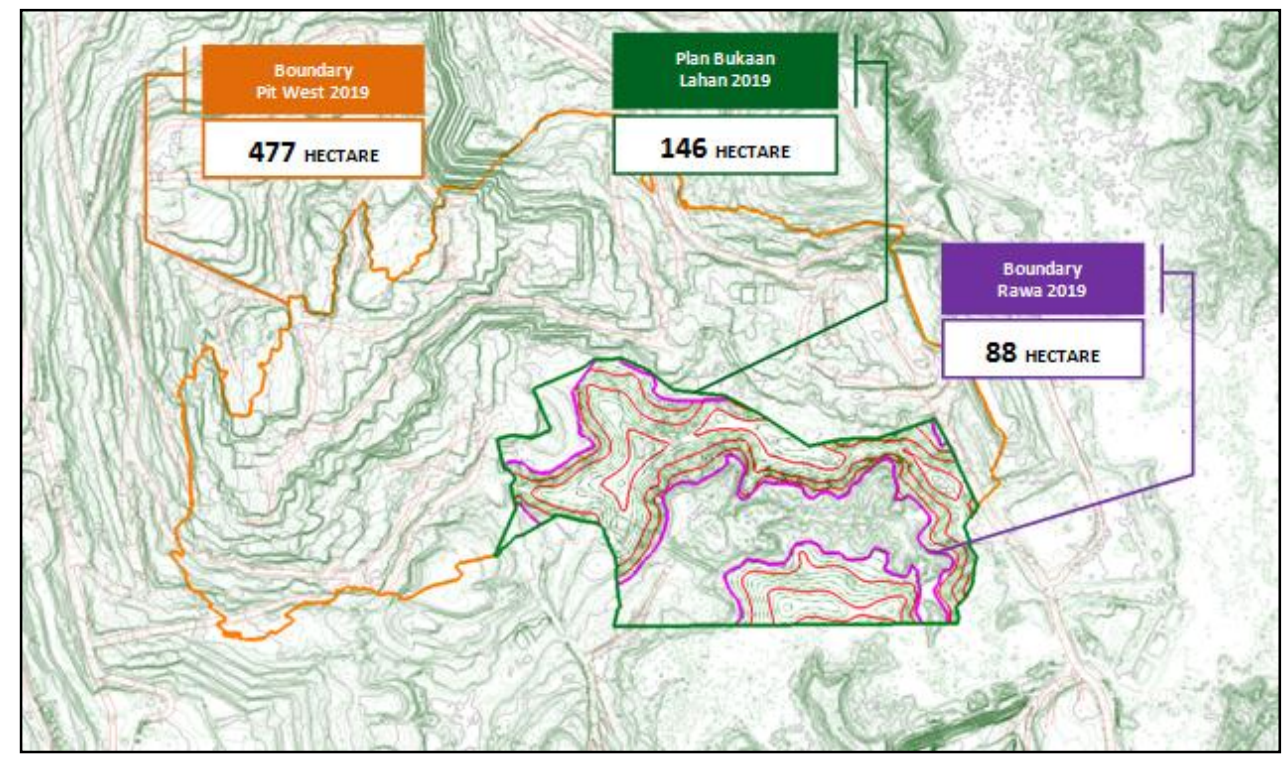

Gambar 1. Area rawa yang masuk dalam rencana bukaan lahan Pit West

Section A-A'
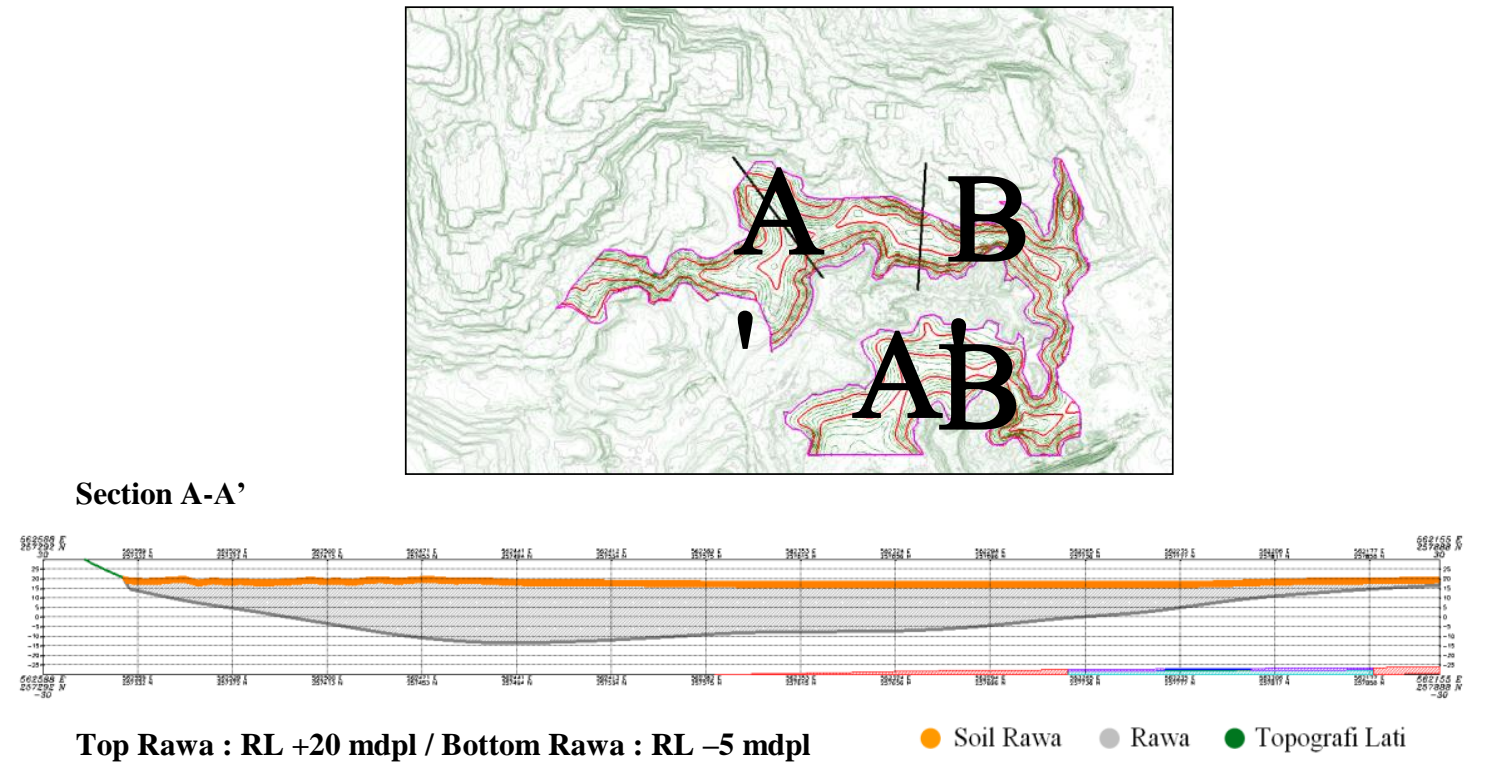

Gambar 2. Section A-A’ rawa Pit West

Department in charge (DIC) project ini adalah short term mine planner, enviro, mining operation, dan pit service. Berdasarkan hasil inspeksi dan observasi di lapangan maka dapat disampaikan PICA seperti tercantum dalam Tabel 1 sebagai awal persiapan dan action yang akan dilakukan berkaitan dengan project. 


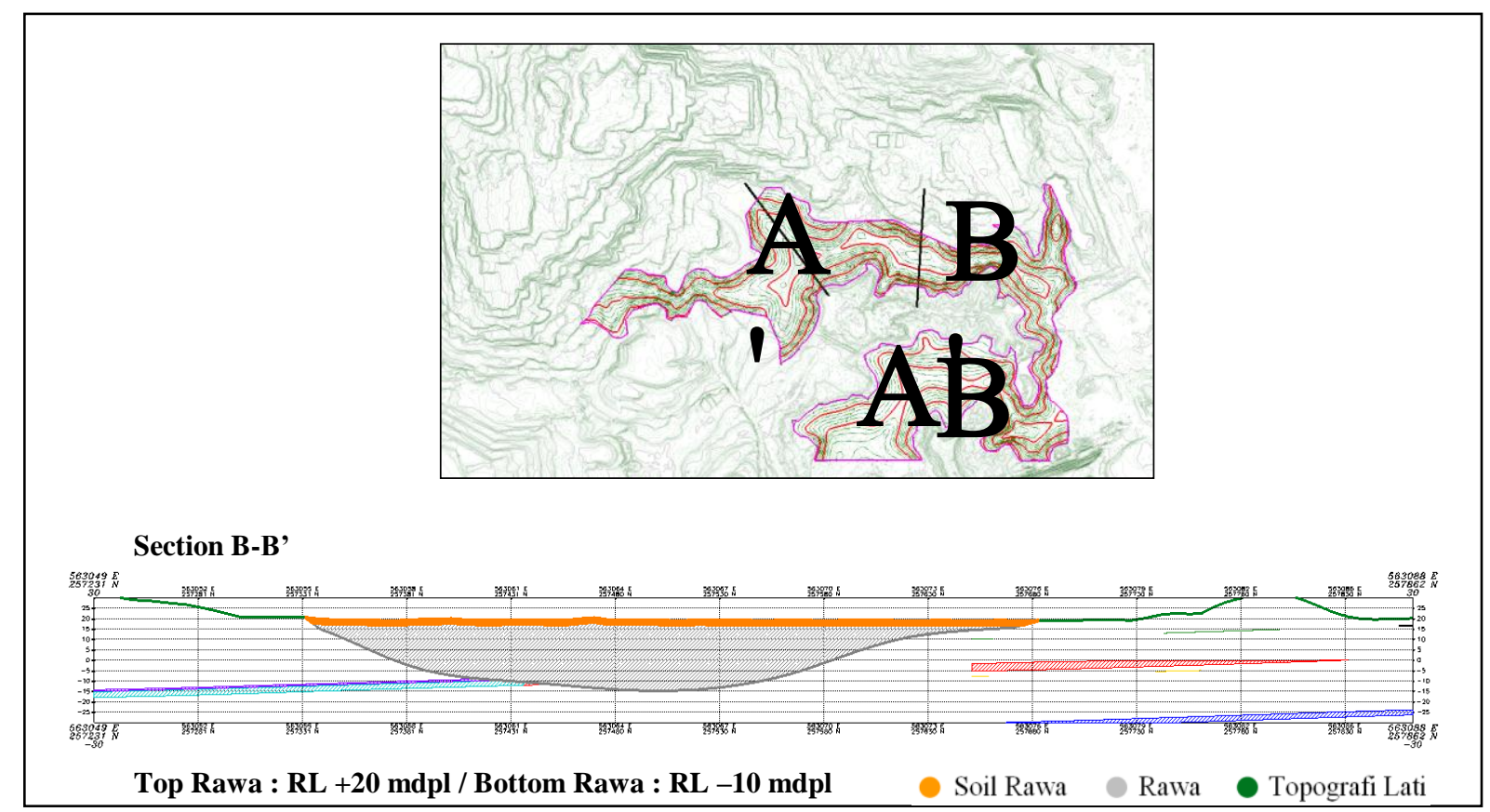

Gambar 3. Section B-B' rawa Pit West

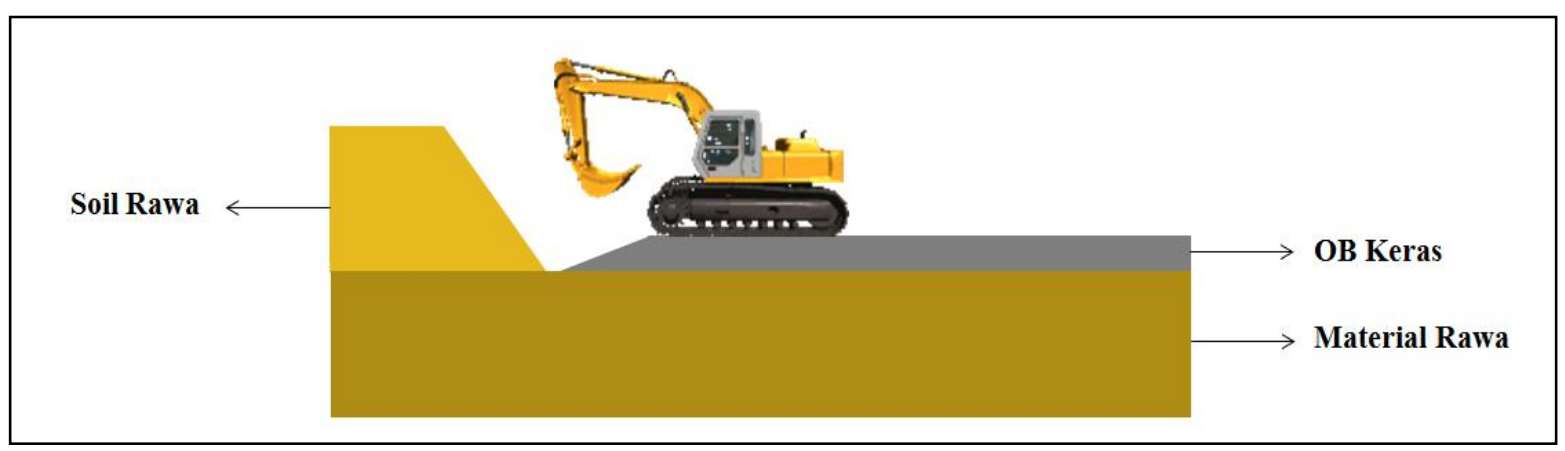

Gambar 4. Layering front loading rawa dengan OB keras sebagai pad excavator

Secara kualitas dan kesuburan tanah dilakukan metode pengambilan sample soil untuk selanjutnya dilakukan uji laboratorium soil rawa yaitu dengan cara sebagai berikut :

1) Metode sampling menggunakan systematic random sampling pada area yang telah di tetapkan yaitu pada Pit West sisi timur (High Wall) dengan ketentuan :

a) Jika kondisi area secara visual homogen maka pengambilan sampling dilakukan pada 2-3 titik per hektar.

b) Jika kondisi area secara visual terlihat heterogen maka jumlah sample yang diambil adalah 4 titik per hektar.

2) Metode pengambilan sample soil area revegetasi pada area dengan kelas umur kurang dari 2 tahun, 2-4 tahun, 4-6 tahun, 8-10 tahun, lebih dari 10 tahun, dan hutan original. Analisa soil revegetasi digunakan sebagai benchmarking untuk mengetahui apakah soil area rawa bisa digunakan atau tidak.

Sample soil dianalisis di laboratorium tanah Fakultas Pertanian Universitas Mulawarman untuk menentukan sifat-sifat soil dan karakteristik soil. Adapun parameter dan metode analisis soil yang digunakan dapat diolihat pada Tabel 2 sebagai berikut. 
Tabel 1. PICA Project Pemanfaatan Soil Rawa

\begin{tabular}{|c|c|c|c|c|}
\hline Perspective & Problem Identification & Corrective Action & $D I C$ & Due Date \\
\hline $\begin{array}{c}\text { Sequence } \\
\text { Pit }\end{array}$ & $\begin{array}{l}\text { Keberlangsungan } \\
\text { development } \text { Pit West di } \\
\text { area rawa dan kebutuhan } \\
\text { revegetasi soil }\end{array}$ & $\begin{array}{l}\text { Join planning terkait pengaturan fleet } \\
\text { material rawa dan metode teknis loading } \\
\text { dengan menggunakan layering soil rawa yang } \\
\text { di ambil adalah 1st layer dan } 2 \text { nd layer soil } \\
\text { rawa }\end{array}$ & ST, MNO & Closed \\
\hline $\begin{array}{l}\text { Disposal } \\
\text { material soil } \\
\quad \text { rawa }\end{array}$ & $\begin{array}{l}\text { Diperlukan penempatan } \\
\text { lokasi disposal soil rawa }\end{array}$ & $\begin{array}{l}\text { Lokasi dumping soil rawa ditentukan pada } \\
\text { area disposal final dan pada area yang flat } \\
\text { Lokasi dumping soil rawa tidak dilakukan } \\
\text { pada area slope disposal } \\
\text { Perapihan soil rawa dilakukan dengan } \\
\text { menggunakan unit PC200 dan Dozer D155 }\end{array}$ & $\begin{array}{l}\text { ST, MNO, } \\
\text { PIT } \\
\text { SERVICE }\end{array}$ & Closed \\
\hline $\begin{array}{l}\text { Kesuburan } \\
\text { soil rawa }\end{array}$ & $\begin{array}{l}\text { Diperlukan analisa } \\
\text { laboratorium terkait } \\
\text { kesuburan soil rawa }\end{array}$ & $\begin{array}{l}\text { Pengambilan sample soil rawa } \\
\text { Uji laboratorium soil rawa } \\
\text { Rekomendasi penggunaan soil rawa }\end{array}$ & ENV & Closed \\
\hline
\end{tabular}

Tabel 2. Parameter dan Metode Analisis Soil yang Digunakan

\begin{tabular}{|c|c|c|c|c|c|}
\hline No & Parameter & Metode Analisis & No & Parameter & $\begin{array}{l}\text { Metode } \\
\text { Analisis }\end{array}$ \\
\hline 1 & $\mathrm{pH}-\mathrm{H} 2 \mathrm{O}$ & pH-meter & 7 & K-tersedia & Morgan \\
\hline 2 & C-Organik & Black dan Walkey & 8 & KTK & NH4OAc pH 7 \\
\hline 3 & N-total & Kjeldahl & 9 & $\begin{array}{l}\mathrm{K}, \mathrm{Na}, \mathrm{Ca}, \mathrm{Mg} \text { - dapat } \\
\text { ditukar }\end{array}$ & AAS \\
\hline 4 & $\mathrm{P}$ dan K-potential & HCI $25 \%$ & 10 & $\%$ Kejenuhan basa & Perhitungan \\
\hline 5 & P-tersedia & Bray I & 11 & $\mathrm{Al}$ dan $\mathrm{H}$ - dapat ditukar & Titrasi \\
\hline 6 & $\mathrm{C} / \mathrm{N}$ organik & Hitung & 12 & $\%$ Kejenuhan Al & Perhitungan \\
\hline
\end{tabular}

\section{HASIL DAN PEMBAHASAN}

Berdasarkan perhitungan potensi lapisan soil diatas rawa yang dapat dimanfaatkan adalah sebesar 2.201.860 BCM. Melihat potensi ini dibentuklah project initiative dengan tujuan memanfaatkan lapisan soil diatas rawa untuk digunakan sebagai media tanam revegetasi. Metode penggalian soil rawa sama dengan metode penggalian lumpur yaitu dengan metode layering.

Secara geometri front loading wajib mengikuti prosedur penggalian dan pembentukan desain lereng pada area material lunak yang telah sesuai dengan kaidah/kajian geoteknik khusus di area tersebut. Pada front loading material lunak terdapat aktivitas layering dan penggalian material lunak dengan ukuran front 2 kali front loading normal, dimana front loading normal adalah $2 \mathrm{x}$ lebar unit terbesar ditambah $1 \mathrm{x}$ radius manuver unit terbesar.

Geometri Front Loading Material Lunak $=2$ x ( 2 x Lebar Unit + Radius Manuver Unit $)$

Material soil yang di loading kemudian di dumping di area disposal final yang telah disiapkan. Area disposal final tersebut wajib diketahui dan disetujui oleh tim short term mine planner, mine operation, dan enviro berkaitan dengan kesesuaian actual dengan design disposal, rencana jalan, 
drainase, dan fasilitas lain sebelum di cover oleh material soil. Ketebalan covering soil menyesuaikan dengan prosedur pengelolaan tanah soil yaitu setebal $1.25 \mathrm{~m}$.

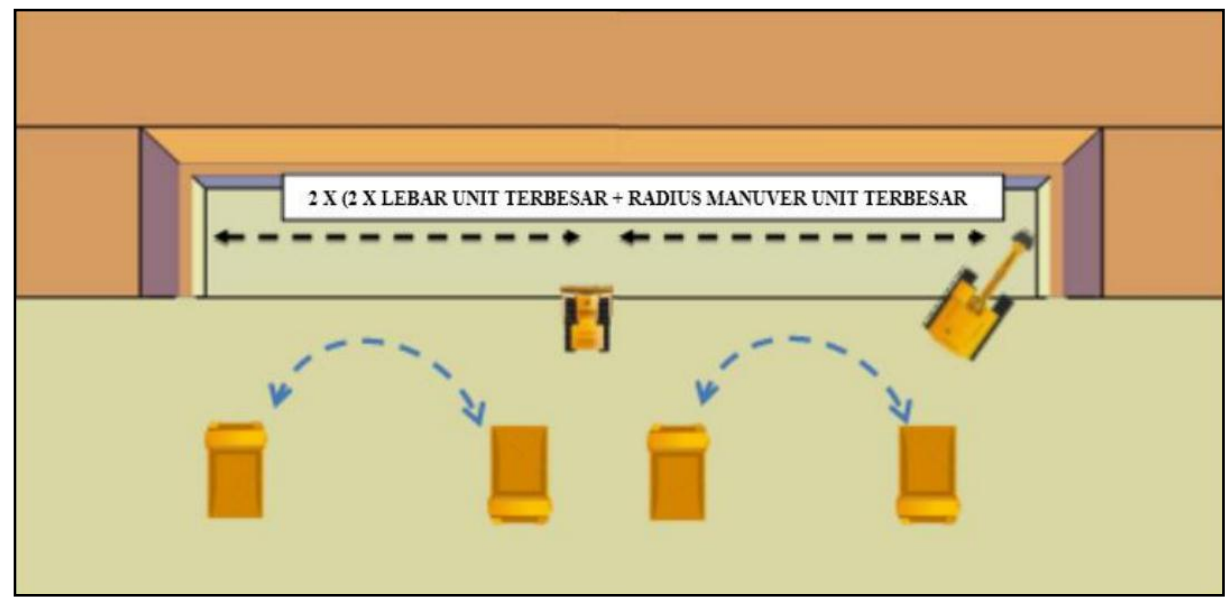

Gambar 5. Geometri Front Loading Material Lunak

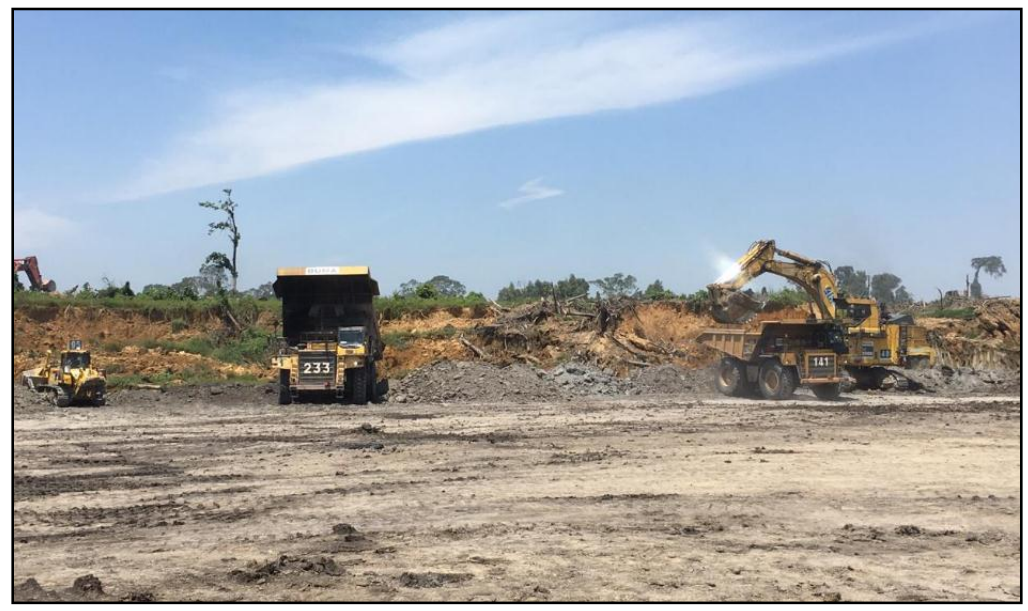

Gambar 6. Proses Loading Soil Rawa dan Layerig Material Overburden

Treatment lapisan soil diatas rawa pada dasarnya sama dengan treatment soil original. Namun karena material dalam kondisi basah dan daya dukung yang lebih lemah maka perapian soil rawa di area disposal menggunakan unit excavator sekelas PC200 dan tidak menggunakan unit dozer. Hal ini dikarenakan unit PC200 dapat memeriksa area pijakannya terlebih dahulu sebelum melakukan perapian.

Melalui project ini area revegetasi yang telah di cover dengan material lapisan soil diatas rawa (November 2018-Juni 2019) sebagai bagian konservasi lingkungan adalah seluas 41,20 Ha dengan pencapaian year to date 2019 revegetasi hingga Juni adalah 100\% (actual 109,11 Ha, plan 108,79 $\mathrm{Ha})$. 


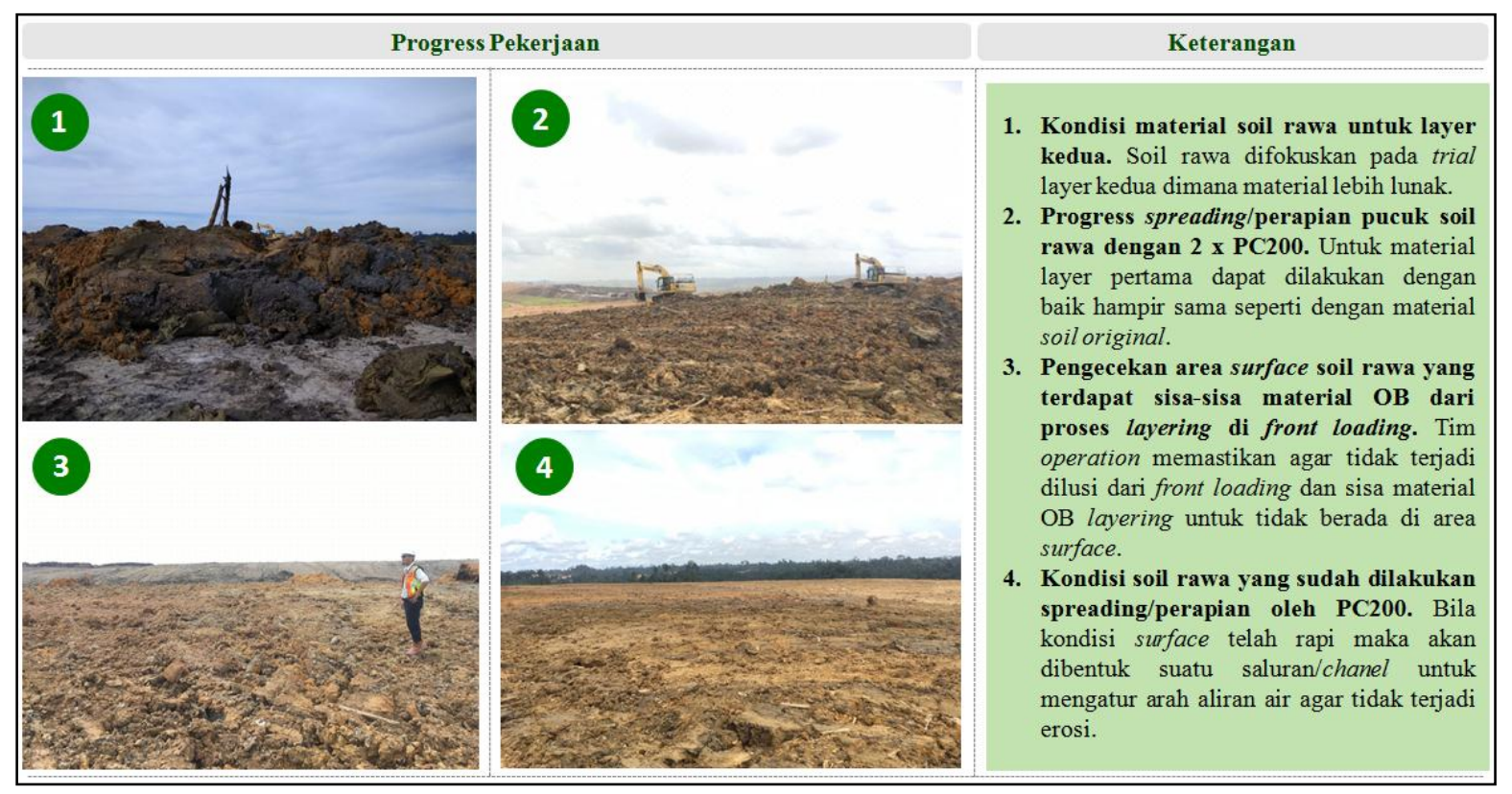

Gambar 7. Proses Pekerjaan Treatment Soil Rawa di Disposal

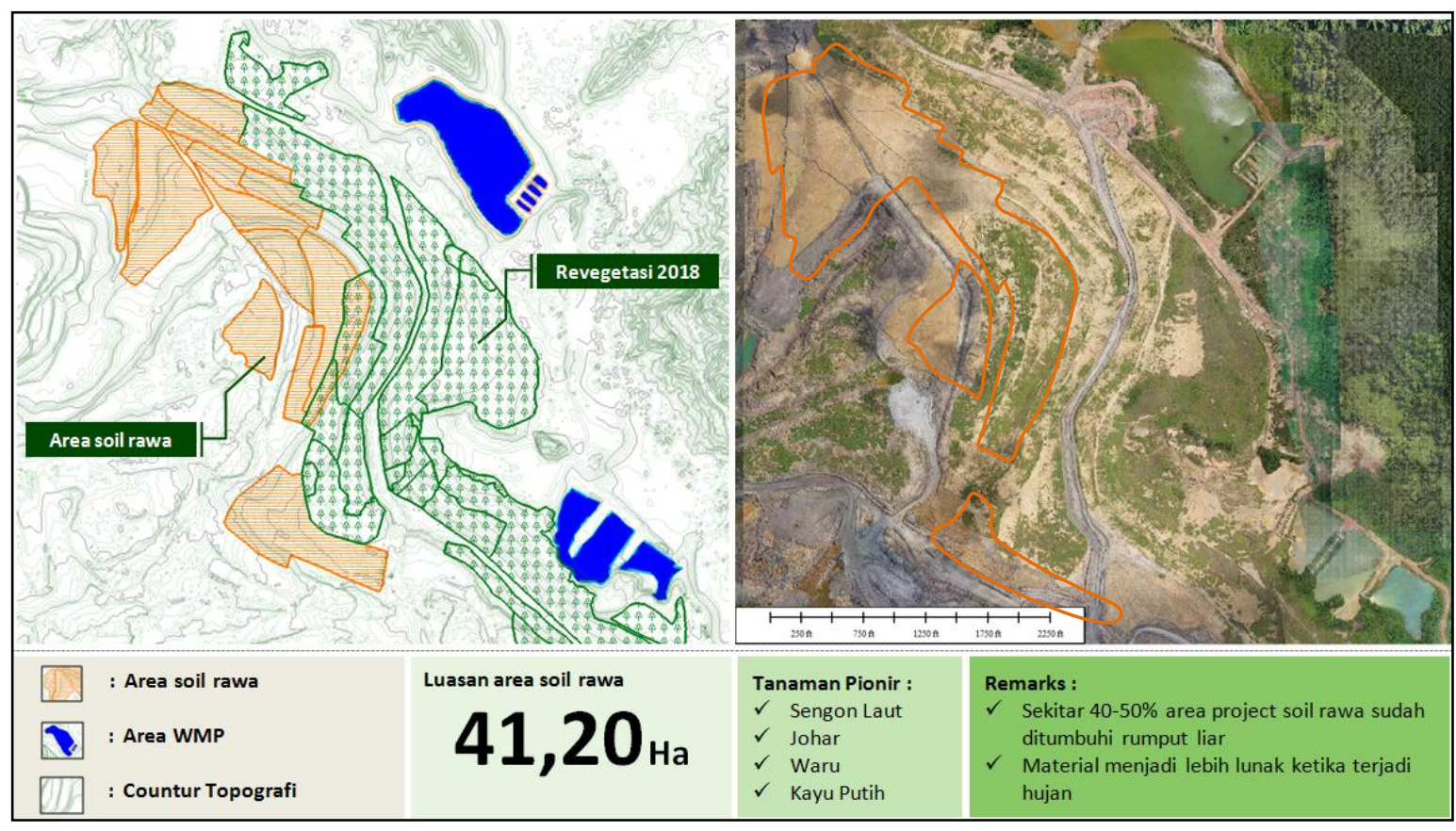

Gambar 8. Area Disposal dengan Pemanfaatan Soil Rawa

Karakteristik tanah site Lati secara keseluruhan masuk dalam kategori ultisol yang masa tanahnya mempunyai karakteristik keasaman yang tinggi dan kandungan unsur hara mikro serta makro yang rendah. 
Tabel 3. Hasil Analisa Soil Area Rawa

\begin{tabular}{|c|c|c|c|c|c|c|c|c|c|c|c|c|c|c|c|c|c|c|c|c|c|c|c|c|c|c|c|}
\hline \multirow{3}{*}{$\begin{array}{c}\text { No } \\
\\
1\end{array}$} & \multicolumn{3}{|c|}{ Kode } & \multicolumn{2}{|c|}{$\mathbf{p H}$} & \multicolumn{2}{|c|}{$\begin{array}{c}\text { C Organik } \\
(\%)\end{array}$} & \multicolumn{2}{|c|}{ N Total (\%) } & \multicolumn{2}{|c|}{ C/N Rasio } & \multicolumn{2}{|c|}{$\begin{array}{c}\mathbf{P}_{2} \mathbf{O}_{5} \\
\text { Tersedia } \\
(\%)\end{array}$} & \multicolumn{2}{|c|}{$\begin{array}{c}\mathrm{K}_{2} \mathrm{O} \\
\text { Tersedia } \\
(\%)\end{array}$} & \multicolumn{6}{|c|}{ Kation Basa (meq/100 g) } & \multirow{2}{*}{\multicolumn{2}{|c|}{$\begin{array}{c}\begin{array}{c}\text { KTK } \\
(\mathrm{meq} / 100 \mathrm{~g})\end{array} \\
\text { Kelas Nilai }\end{array}$}} & \multirow{2}{*}{\multicolumn{2}{|c|}{$\begin{array}{c}\begin{array}{c}\text { Kej. Basa } \\
(\%)\end{array} \\
\text { Kelas Nilai }\end{array}$}} & \multirow{2}{*}{\multicolumn{2}{|c|}{$\begin{array}{l}\text { Kej. Al (\%) } \\
\text { Kelas Nilai }\end{array}$}} \\
\hline & Sampel & laman & Lokasi & \multicolumn{2}{|c|}{$\begin{array}{c}\text { Kelas } \\
\text { Keasaman }\end{array}$} & \multicolumn{2}{|c|}{ Kelas Nilai } & \multicolumn{2}{|c|}{ Kelas Nilai } & \multicolumn{2}{|c|}{ Kelas Nilai } & \multicolumn{2}{|c|}{ Kelas Nilai } & \multicolumn{2}{|c|}{ Kelas Nilai } & \multicolumn{2}{|c|}{ Kelas Nilai } & \multicolumn{2}{|c|}{ Kelas Nilai } & \multicolumn{2}{|c|}{ Kelas Nilai } & & & & & & \\
\hline & $\begin{array}{l}\text { Sampel A/ } \\
\text { Soil Rawa }\end{array}$ & 25 & $\begin{array}{l}\text { IPD East } \\
\text { Elv }+90\end{array}$ & 3,91 & SM & 2,30 & $\mathrm{~s}$ & 0,22 & $\mathrm{~s}$ & 10,45 & $\mathrm{R}$ & 8,40 & $\mathrm{R}$ & 40,96 & S & 2,70 & $\mathrm{R}$ & 1,81 & $\mathrm{~s}$ & 0,26 & $\mathrm{R}$ & 7,36 & $\mathrm{R}$ & 68,75 & $\mathrm{~T}$ & 20,65 & $\mathrm{~s}$ \\
\hline 2 & $\begin{array}{l}\text { Sampel B/ } \\
\text { Soil Rawa }\end{array}$ & 30 & $\begin{array}{l}\text { IPD East } \\
\text { Elv +90 }\end{array}$ & 4,47 & SM & 2,02 & S & 0,20 & S & 10,10 & $\mathrm{R}$ & 12,00 & $\mathrm{~S}$ & 60,43 & $\mathrm{~S}$ & 3,20 & $\mathrm{R}$ & 2,02 & S & 0,33 & $\mathrm{R}$ & 6,21 & $\mathrm{R}$ & 95,17 & $\mathrm{~T}$ & 3,22 & $\mathrm{R}$ \\
\hline 3 & $\begin{array}{l}\text { Sampel C/ } \\
\text { Soil Rawa }\end{array}$ & 75 & $\begin{array}{l}\text { IPD East } \\
\text { Elv }+90\end{array}$ & 4,75 & M & 1,78 & $\mathrm{R}$ & 0,17 & $\mathrm{R}$ & 10,47 & $\mathrm{R}$ & 8,00 & $\mathrm{R}$ & 90,44 & $\mathrm{~T}$ & 4,22 & $\mathrm{R}$ & 0,88 & $\mathrm{R}$ & 0,38 & $\mathrm{R}$ & 6,33 & $\mathrm{R}$ & 93,68 & $\mathrm{~T}$ & 6,00 & $\mathrm{R}$ \\
\hline 4 & $\begin{array}{l}\text { Sampel D/ } \\
\text { Soil Rawa }\end{array}$ & 100 & $\begin{array}{l}\text { IPD East } \\
\text { Elv }+90\end{array}$ & 3,25 & SM & 1,99 & $\mathrm{R}$ & 0,27 & S & 7,37 & $\mathrm{R}$ & 10,80 & $\mathrm{R}$ & 40,96 & S & 4,03 & $\mathrm{R}$ & 1,21 & S & 0,26 & $\mathrm{R}$ & 9,01 & $\mathrm{R}$ & 64,48 & $\mathrm{~T}$ & 23,31 & $\mathrm{~T}$ \\
\hline 5 & $\begin{array}{l}\text { Sampel E/ } \\
\text { Soil Disp }\end{array}$ & 30 & $\begin{array}{c}\text { OPD ON2 } \\
\text { Elv }+40\end{array}$ & 4,53 & M & 1,85 & $\mathrm{R}$ & 0,20 & S & 9,25 & $\mathrm{R}$ & 4,80 & $\mathrm{R}$ & 47,78 & S & 2,37 & $\mathrm{R}$ & 2,19 & S & 0,26 & $\mathrm{R}$ & 5,31 & $\mathrm{R}$ & 93,22 & $\mathrm{~T}$ & 3,77 & $\mathrm{R}$ \\
\hline 6 & $\begin{array}{l}\text { Sampel F/ } \\
\text { Soil Disp }\end{array}$ & 60 & $\begin{array}{c}\text { OPD ON2 } \\
\text { Elv }+40\end{array}$ & 4,65 & $\mathrm{M}$ & 1,29 & $\mathrm{R}$ & 0,15 & $\mathrm{R}$ & 8,60 & $\mathrm{R}$ & 6,40 & $\mathrm{R}$ & 71,67 & $\mathrm{~T}$ & 2,54 & $\mathrm{R}$ & 3,06 & S & 0,29 & $\mathrm{R}$ & 9,00 & $\mathrm{R}$ & 66,67 & $\mathrm{~T}$ & 21,11 & $\mathrm{~T}$ \\
\hline 7 & $\begin{array}{l}\text { Sampel G/ } \\
\text { Soil Disp }\end{array}$ & 90 & $\begin{array}{c}\text { OPD ON2 } \\
\text { Elv }+40\end{array}$ & 4,45 & SM & 1,00 & $\mathrm{R}$ & 0,17 & $\mathrm{R}$ & 5,88 & $\mathrm{R}$ & 6,80 & $\mathrm{R}$ & 51,19 & $\mathrm{~s}$ & 3,87 & $\mathrm{R}$ & 2,03 & $\mathrm{~s}$ & 0,31 & $\mathrm{R}$ & 9,59 & $\mathrm{R}$ & 67,05 & $\mathrm{~T}$ & 20,86 & $\mathrm{~s}$ \\
\hline 8 & $\begin{array}{l}\text { Sampel H/ } \\
\text { Soil Rawa }\end{array}$ & 100 & $\begin{array}{l}\text { IPD East } \\
\text { Elv }+40\end{array}$ & 4,65 & M & 2,30 & $\mathrm{~s}$ & 0,25 & $\mathrm{~S}$ & 9,20 & $\mathrm{R}$ & 4,40 & $\mathrm{R}$ & 91,30 & $\mathrm{~T}$ & 3,70 & $\mathrm{R}$ & 0,93 & $\mathrm{R}$ & 0,37 & $\mathrm{R}$ & 9,09 & $\mathrm{R}$ & 58,20 & $\mathrm{~T}$ & 26,40 & $\mathrm{~T}$ \\
\hline 9 & $\begin{array}{c}\text { Sampel I/ } \\
\text { Soil Rawa }\end{array}$ & 200 & $\begin{array}{l}\text { IPD East } \\
\text { Elv }+40\end{array}$ & 4,22 & SM & 2,90 & $\mathrm{~s}$ & 0,32 & $\mathrm{~s}$ & 9,06 & $\mathrm{R}$ & 6,80 & $\mathrm{R}$ & 76,79 & $\mathrm{~T}$ & 4,37 & $\mathrm{R}$ & 0,58 & $\mathrm{R}$ & 0,39 & $\mathrm{R}$ & 7,14 & $\mathrm{R}$ & 77,59 & $\mathrm{~T}$ & 15,41 & $\mathrm{~s}$ \\
\hline \multicolumn{4}{|c|}{ Nilai Minimum } & 3,25 & SM & 1,00 & $\mathbf{R}$ & 0,15 & $\mathbf{R}$ & 5,88 & $\mathbf{R}$ & 4,40 & $\mathbf{R}$ & 40,96 & $\mathbf{S}$ & 2,37 & $\mathbf{R}$ & 0,58 & $\mathbf{R}$ & 0,26 & $\mathbf{R}$ & 5,31 & $\mathbf{R}$ & 58,20 & $\mathbf{T}$ & 3,22 & $\mathbf{R}$ \\
\hline \multicolumn{4}{|c|}{ Nilai Maximum } & 4,75 & $\mathbf{M}$ & 2,90 & $\mathbf{S}$ & 0,32 & $\mathbf{S}$ & 10,47 & $\mathbf{R}$ & 12,00 & $\mathbf{S}$ & 91,30 & $\mathbf{T}$ & 4,37 & $\mathbf{R}$ & 3,06 & $\mathbf{S}$ & 0,39 & $\mathbf{R}$ & $\mathbf{9 , 5 9}$ & $\mathbf{R}$ & 95,17 & $\mathbf{T}$ & 26,40 & $\mathbf{T}$ \\
\hline \multicolumn{4}{|c|}{ Nilai Average } & 4,32 & SM & 1,94 & $\mathbf{R}$ & 0,22 & $\mathbf{S}$ & 8,93 & $\mathbf{R}$ & 7,60 & $\mathbf{R}$ & 63,61 & $\mathbf{S}$ & 3,44 & $\mathbf{R}$ & 1,63 & $\mathbf{S}$ & $\mathbf{0 , 3 2}$ & $\mathbf{R}$ & 7,67 & $\mathbf{R}$ & 76,09 & $\mathbf{T}$ & 15,64 & $\mathbf{S}$ \\
\hline
\end{tabular}


Tabel 4. Hasil Analisa Soil Area Revegetasi

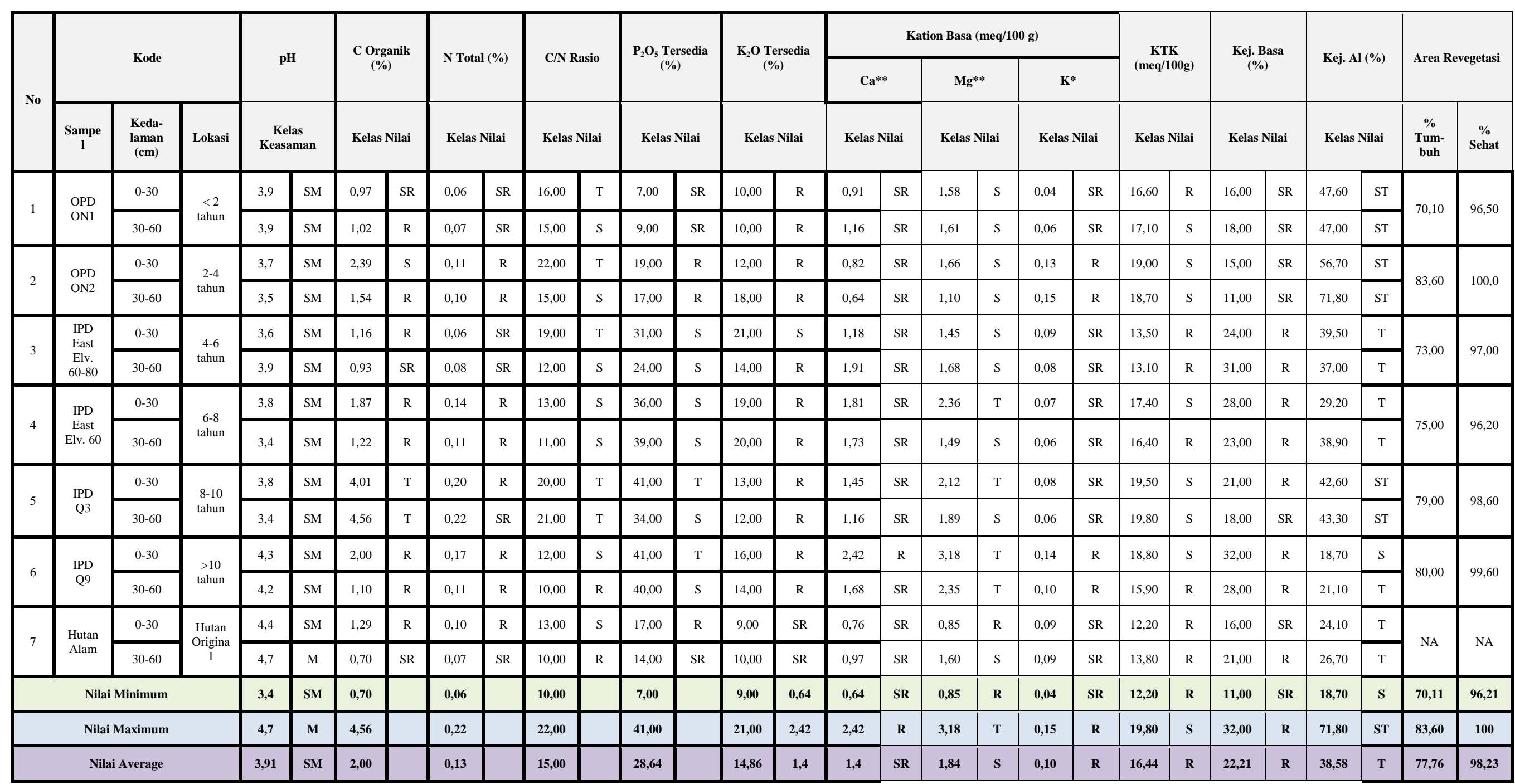


Dari tabel analisa soil sebaran keasaman pada area rawa rata-rata $\mathrm{pH} 4.32$ sedangkan pada revegetasi rata-rata $\mathrm{pH} 3.91$ dan kandungan unsur hara makro N, P, K mempunyai sebaran rendah sampai dengan tinggi sedangkan pada area revegetasi mempunyai sebaran sangat rendah sampai dengan tinggi.

Jenis vegetasi pada area sampling sebaran soil dengan karakteristik soil seperti pada site Lati yang paling dominan dan mampu beradaptasi adalah :

1) Sengon laut (Paraserianthes falcataria)

2) Kayu putih (Melaleuca leucadendron)

3) Gempol (Nauclea orientalis)

4) Johar (Cassia siamea)

5) Waru (Hibiscus spp)

6) Meranti Kahoi (Shorea balangeran)

\section{KESIMPULAN}

Berdasarkan hasil analisis dan pembahasan dapat disimpulkan sebagai berikut :

1) Karakteristik tanah site Lati secara keseluruhan masuk dalam kategori ultisol yang masa tanah mempunyai karakteristik keasaman yang tinggi. Kondisi soil area rawa mempunyai tingkat keasaman lebih baik dengan rata-rata $\mathrm{pH}$ 4,32 sedangkan pada area revegetasi $\mathrm{pH}$ rata-rata 3,91.

2) Secara keseluruhan sesuai hasil uji laboratorium kandungan unsur hara lapisan soil diatas rawa hampir sama baik dengan soil pada area original dan masuk pada cluster rendah, sedang dan tinggi.

3) Berdasarkan kajian dan rekomendasi enviro department lapisan soil diatas rawa secara kandungan sifat kimia layak untuk digunakan sebagai media pertumbuhan tanaman untuk revegetasi.

4) Melalui project ini area revegetasi yang telah di cover dengan material lapisan soil diatas rawa (November 2018-Juni 2019) sebagai bagian konservasi lingkungan adalah seluas 41,20 Ha dengan pencapaian year to date 2019 revegetasi hingga Juni adalah 100\% (actual 109,11 Ha, plan 108,79 Ha).

\section{DAFTAR PUSTAKA}

Adriansyah, Yan. Arintoko Saputro. (2019): Prosedur Penggalian dan Pembentukan Desain Lereng pada Area Material Lunak. Berau. PT. Berau Coal.

Hudiantoro, Arief. Salahudin Al Rasyid. Rahmantha P.A. Dian Permana Putra. Lukman Hakim. Wahyudi. (2018): Prosedur Pengelolaan Tanah (soil). Berau. PT. Berau Coal

Monkhouse, F.J. dan J. Small. (1978): A Dictionary of the Natural Environment. London. Edward Arnold.

Muhammad Masyhuri. (2019): Laporan Kajian Analisa Kesuburan Soil pada Areal Rawa Site Lati. Berau. PT. Berau Coal. 